\title{
Emerging tumor spheroids technologies for 3D in vitro cancer modeling ${ }^{\text {is }}$
}

\author{
Tânia Rodrigues ${ }^{\mathrm{a}, \mathrm{b}, 1}$, Banani Kundu ${ }^{\mathrm{a}, \mathrm{b}, 1}$, Joana Silva-Correia ${ }^{\mathrm{a}, \mathrm{b}}$, S.C. Kundu ${ }^{\mathrm{a}, \mathrm{b}}$, \\ Joaquim M. Oliveira ${ }^{\mathrm{a}, \mathrm{b}, \mathrm{c}}$, Rui L. Reis ${ }^{\mathrm{a}, \mathrm{b}, \mathrm{c}}$, Vitor M. Correlo ${ }^{\mathrm{a}, \mathrm{b}, \mathrm{c}, *}$ \\ a 3B's Research Group - Biomaterials, Biodegradables and Biomimetics, University of Minho, Headquarters of the European Institute of Excellence on Tissue Engineering \\ and Regenerative Medicine, AvePark, Zona Industrial da Gandra, 4805-017 Barco, Guimarães, Portugal \\ b ICVS/3B's - PT Government Associate Laboratory, Braga/Guimarães, Portugal \\ ${ }^{\mathrm{c}}$ The Discoveries Centre for Regenerative and Precision Medicine, Headquarters at University of Minho, Avepark, 4805-017 Barco, Guimarães, Portugal
}

\section{A R T I C L E I N F O}

\section{Keywords:}

Metastasis

3D tumor models

Multicellular tumor spheroids

Bioprinting

Biomaterials

\begin{abstract}
A B S T R A C T
Cancer is a leading cause of mortality and morbidity worldwide. Around $90 \%$ of deaths are caused by metastasis and just $10 \%$ by primary tumor. The advancement of treatment approaches is not at the same rhythm of the disease; making cancer a focal target of biomedical research. To enhance the understanding and prompts the therapeutic delivery; concepts of tissue engineering are applied in the development of in vitro models that can bridge between 2D cell culture and animal models, mimicking tissue microenvironment. Tumor spheroid represents highly suitable 3D organoid-like framework elucidating the intra and inter cellular signaling of cancer, like that formed in physiological niche. However, spheroids are of limited value in studying critical biological phenomenon such as tumor-stroma interactions involving extra cellular matrix or immune system. Therefore, a compelling need of tailoring spheroid technologies with physiologically relevant biomaterials or in silico models, is ever emerging. The diagnostic and prognostic role of spheroids rearrangements within biomaterials or microfluidic channel is indicative of patient management; particularly for the decision of targeted therapy. Fragmented information on available in vitro spheroid models and lack of critical analysis on transformation aspects of these strategies; pushes the urge to comprehensively overview the recent technological advancements (e.g. bioprinting, micro-fluidic technologies or use of biomaterials to attain the third dimension) in the shed of translationable cancer research. In present article, relationships between current models and their possible exploitation in clinical success is explored with the highlight of existing challenges in defining therapeutic targets and screening of drug efficacy.
\end{abstract}

\section{Biological fundaments of metastasis progression}

The alterations in oncogenes and tumor suppressors underlie the autonomous defects in cells; the characteristics of cancer initiation within a healthy non-transformed cellular microenvironment. But tumors are not simply autonomous neoplastic cells; instead the cross-talk among tumorous or malignant and non-malignant cells, signals and secretory proteins (such as cytokines) influences cancer development, metastasis formation and dissemination (Barcellos-Hoff, Lyden, \& Wang, 2013; Bremnes et al., 2011). Metastasis is "the spread of cancer cells from primary tumor to secondary locations within the body" (Barcellos-Hoff et al., 2013). The cascade events of metastasis start with the growth of primary tumor cells, which needs the supply of blood to support their metabolism - the phenomenon known as angiogenesis. The proliferating tumor cells commandees available vasculature or stimulate neovessel generation for continuous supply of oxygen, nutrients and growth factors. The rapid proliferation soon exhausts the supply of nutrient and oxygen; becomes hypoxic (Thoma, Zimmermann, Agarkova, Kelm, \& Krek, 2014). The newly formed blood vessel offers the escape route to tumor cells, that then enter into circulatory system (such as blood or lymphatic system) - the process known as intravation. Migratory tumor cells surviving within the circulation, extravasate into a near or far guest-tissue/organ and start formation of a secondary tumor mass as depicted in Fig. 1. Despite of

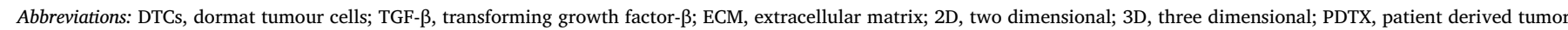
xenografts; MCTS, multi-cellular tumor spheroid; Me-GG, methacrylate - Gellan gum

As Associate editor: B. Teicher

* Corresponding author. 3B's Research Group - Biomaterials, Biodegradables and Biomimetics, University of Minho, Headquarters of the European Institute of Excellence on Tissue Engineering and Regenerative Medicine, AvePark, Zona Industrial da Gandra, 4805-017 Barco, Guimarães, Portugal.

E-mail address: vitorcorrelo@dep.uminho.pt (V.M. Correlo).

${ }^{1}$ Contributed equally.
} 


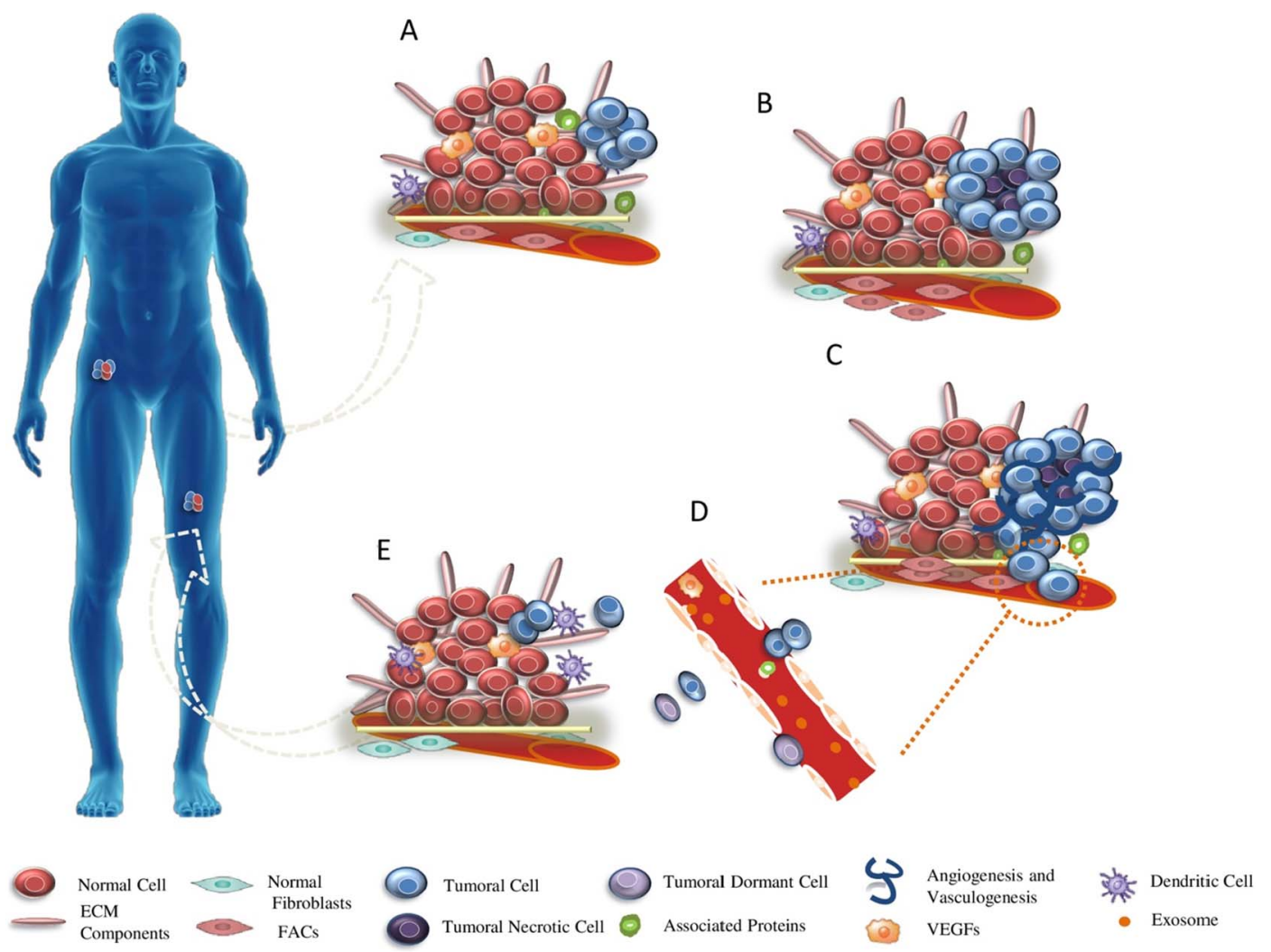

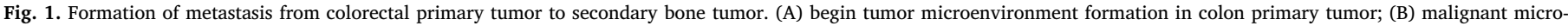

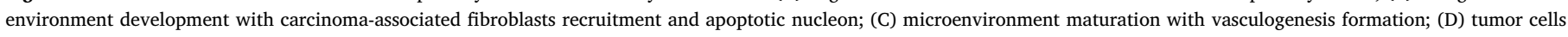
invading circulatory system by extravasation towards a new tissue/organ; (E) new host colonization forming a secondary tumor in bone.

available information in hand is not enough for addressing major questions, namely: how cancer cells learn to become metastatic? Why tumor cell colonizes at specific sites? Which is "the signal" for new tissue/organ selection? Recently, exosomes are recognized as crucial factor in regulating organ-specific metastasis selection (Hoshino et al., 2015; Kuzet \& Gaggioli, 2016).

Following the arrival at secondary site, circulating cancer cells may turn into solitary cells or initiate small pre-angiogenic metastases or larger vascularized metastases (Chambers, Groom, \& MacDonald, 2002). In each case, a small subset of cells executes the pre-defined action, major portion either undergoes dormancy or die. The dormant solitary cells refer as dormat tumor cells (DTCs) that neither proliferate nor died; remaining as silent (Cuperlovic-Culf, Culf, Touaibia, \& Lefort, 2012; Hensel, Flaig, \& Theodorescu, 2013). DTCs are identified as potential target in premature metastasis detection, concretely in mesenchymal transition (Hensel et al., 2013) and extensively explored as a prognostic marker in various solid cancers or complementary strategy for metastasis monitoring (Giuliano et al., 2014; Lohr et al., 2014). However, solitary cells and micrometastases are clinically undetectable; only vascularized metastases are clinically detectable. Up till now cellular markers such as Ki-67 (to detect proliferation), terminal deoxynucleotidyl transferase dUTP labelling (TUNEL) assay and expression of M30 (to detect apoptosis) (Hensel et al., 2013; Newbold, Martin, Cullinane, \& Bots, 2014) are available to identify DTCs.

Cancer stroma contains few fibroblasts, mesenchymal cell types distinctive to each tissue type embedded within the proteinaceous network of extracellular matrix (more distinguishably collagen, elastin, fibrin and fibronectin) (Amann et al., 2014; Kimlin, Casagrande, \& Virador, 2013; Nyga, Cheema, \& Loizidou, 2011). At the intravation front stromal changes take place, such as appearance of carcinoma-associated fibroblasts (CAFs); which is transdifferentiated from the normal fibroblasts in presence of cancer-driven cytokine, Transforming
Growth Factor- $\beta$ (TGF- $\beta$ ) (Azarin et al., 2015; Bremnes et al., 2011; Kuchnio et al., 2015; Ursini-Siegel \& Siegel, 2016). CAFs are responsible for tumor cells invasion and regulation of tumorigenesis by inducing differentiation of endothelial cells into capillary-like microvasculature using cell surface receptor integrins (Cuperlovic-Culf et al., 2012; Joyce \& Pollard, 2009). Immune and inflammatory cell activates the production of chemokines, cytokines and exosomes that involve in remodeling of local tissue; contributing to resistance to traditional chemotherapy (Bremnes et al., 2011).

Other relevant mechanisms associated with the success of tumor development includes involvement of nerves in dissemination of tumor (Amit, Na'ara, \& Gil, 2016). Stellate cells (star shaped cells radiating from cell body during dendritic processes) activates on exposure to premalignant cells, malignant cells, hypoxia and inflammation (Vonlaufen et al., 2008). TGF- $\beta$ expressed by cancer cells stimulates stellate cells, results in enhanced expression of matrix metalloproteinases causing the degradation of peri-neural extracellular matrix (ECM) and migration of cancer cells through tissue (Pantel \& Brakenhoff, 2004). The injured nerve regenerates nerve growth factor and neurturin that recruit macrophages; which further releases glial cell derived neurotrophic factor in support to neural tracking and cancer cell invasion (Amit et al., 2016). The cross-talk between neuron-tumor enhances cancer cell adhesion and further secretion of neurotrophin 3, which triggers Schwann cells involvement. Schwann cells draw cancer cells into peri-neural niche and recruit them to degrade peri-neural ECM facilitating the survival, migration and cancer invasiveness.

Regardless of current understanding, the incompetence to treat metastasis results cancer-related deaths; challenging modern oncologists up till now. Because of these uncertainties, it is necessary to develop more realistic pre-clinical models that allow to gain the underlying insight on the molecular mechanisms driving metastasis formation and progression (Alemany-Ribes \& Semino, 2014; Colacino, 
2016). The state-of-art of cancer research presently involves in investigating the signature of cancer cells on its microenvironment or vice-versa employing the principles of tissue engineering and the structure-function relationship of engineered construct to reveal chemotherapeutics effects that are critically summarized in several recent reviews (Eglen \& Klein, 2017; Fang \& Eglen, 2017). The present review integrates the literatures published on spheroid culture along with mathematical models, since we last review the field (Carvalho, Lima, Reis, Correlo, \& Oliveira, 2015) to update the possibility of exploiting them as predictive tools for creating complex 3D disease environment or drug discovery.

\section{Pre-clinical models for metastasis}

The percentage of transition of cancer therapeutics into clinical success is remarkably low due to sub-optimal pre-clinical validation, inherently complicated nature of disease and limited pre-clinical assay tools (Begley \& Ellis, 2012). The complete expense and complexity of cancer microenvironmental cues experienced by cancer cells during metastatic cascade needs to be studied using appropriate metastatic models for the improvement of therapeutic outcome. Both non-animal and animal models are exploited in preclinical studies (Colacino, 2016; Dranoff, 2011; van Marion, Domanska, Timmer-Bosscha, \& Walenkamp, 2016).

The basic 3D organotypic culture system in cancer modeling has adapted $\sim 40$ years ago; considerably contributing to the insight of cellular response towards chemotherapy (Hickman et al., 2014), hyperthermia (Dubessy, Merlin, Marchal, \& Guillemin, 2000) and radiotherapy-photodynamic treatment (Desoize \& Jardillier, 2000). The success of cancer spheroids as high-throughput analysis system is regulated on choice of appropriate model as per the therapeutic requirement (Costa et al., 2016). Mono-culture of tumor cells into spheroid serves as prevailing tool to investigate the regulators of tumor micro-environment or responsiveness of therapeutics associated with metabolic and proliferative gradients such as altered sensitivity of hypoxic tumor cells or chemotherapeutic resistance (Shield, Ackland, Ahmed, \& Rice, 2009). It also greatly contribute to pronounce effect of radio-sensitization in 3D organotypic setting; particularly transient delay in $G_{2}$ phase, induction of apoptosis and onset of DNA strand break. However, mono cell type spheroid culture system lacks heterogenous cancerous stromal compartment. Investigators address this issue by co-culturing cancer cells with fibroblasts (Gottfried, Kunz-Schughart, Andreesen, \& Kreutz, 2006), immune cells (Orre \& Rogers, 1999) or stem cells (Wang et al., 2010). Nevertheless, the study of systemic cell spread or preferential homing to specific organ needs the involvement of living system, therefore, inclusion of in vivo models is needed.

Models such as fruit fly (Drosophila melanogaster), zebrafish (Danio rerio) provide the in vivo microenvironment to cancer cells to grow (Alemany-Ribes \& Semino, 2014; van Marion et al., 2016). However, lack of various non-conserved sequences limits the recapitulation of genetic complexity of human tumors in zebrafish (Danio rerio) (Alemany-Ribes \& Semino, 2014; van Marion et al., 2016). Chorioallantoic membrane (CAM) of fertilized chicken eggs serves suitable in investigating angiogenesis, extravation and colonization but limits with short assay span of 18 days (Alemany-Ribes \& Semino, 2014; van Marion et al., 2016).

For large scale study of complex metastatic process laboratory animals are included. The most common used animal model for deciphering malignant cancer still remains the mouse (Daphu et al., 2013; Li, 2015). Preclinical primary or secondary metastatic xenograft models using mouse able to recapitulate critical aspects of tumor development; but of limited value from the fact that human tumor cells are implanted and metastasized into an incompatible murine tissue environment. The xenograft models are also increasingly being criticized for their negative impression of inter-species barriers that question the clinical relevance of these studies (Lee et al., 2012; Siolas \& Hannon, 2013).
Further, the use of immune-compromised host animals; particularly non-obese severe diabetic immune-deficient species (Dranoff, 2011; Hibberd, Cossigny, \& Quan, 2013; Li, 2015). Immunosurveillance is a regulatory phenomenon of tumor stroma; significantly contributing to tumor initiation, progression, metastasis and therapeutic responses. As a result, tumor grows faster in immune compromised animals compared to wild type immunocompetent one (Engel et al., 1996). In addition, continuous use of cell lines procures diverged expression of genes compared to parental gene expression (Alemany-Ribes \& Semino, 2014; van Marion et al., 2016). As a consequence, patient derived tumor xenografts (PDTX) are in practice (Tentler et al., 2012; Williams, Anderson, Santaguida, \& Dylla, 2013). PDTXs are promising for development of personalized anti-cancer therapies, biomarkers and drug screening. Additional value is added to PDTX in case of rare cancers where pre-clinical models are absent (Hidalgo et al., 2011). However, considerable time and cost burden of PDTX tumor models along with diversity in subtypes in cancer patients limits its extensive use (Williams et al., 2013).

Full murine models associated with metastasis modeling are broadly categorized into two groups; syngeneic (fully immunocompetent animal model) and genetically modified (Alemany-Ribes \& Semino, 2014; van Marion et al., 2016). In syngeneic model, both host and graft are of same species (Khanna \& Hunter, 2005). Knock-in or Knock-out gene mutations are used in dissemination of cancer; causing change in metastatic potential of resultant cancer cells. In genetically modified cancer animal models, tumor develops at its natural sites and metastasize to distant organ in presence of immune system comparable to that of human (Khanna \& Hunter, 2005). The earliest observation by Dr. Loessner (Loessner, Little, Pettet, \& Hutmacher, 2013) reveals the spheroids and tumor tissues obtained from xenografts are softer than ovarian tissue. However, whether cancer cells mechanically pre-conditioning their metastatic site or not is still elusive. The overview, advantage and limitations of the existing models are depicted in Table 1.

The constraint of existing models needs improvement for better translation of patient-specific treatment. Development of sophisticated animal models and/or patient-unique ex vivo systems like organoids in association with suitable read-out system may facilitate the therapeutic translation. One of the promising strategies is incorporation of biomaterials into $3 \mathrm{D}$ cancer culture system. According to literature, the missing gap of spheres growing in liquid culture media, is ECM (Hickman et al., 2014). ECM is not an inert compartment; instead an interactive component critically regulating the differentiation and invasion of cancer cells. Cell surface receptor $\beta 1$-integrin mediates adhesion to ECM, up-regulates tumorigenicity in hematological and epithelial malignancies and imparts doxorubicin and melphalan resistance to small cell lung cancer and multiple myeloma cells; termed as celladhesion-mediated drug resistance (Correia \& Bissell, 2012; Sethi et al., 1999). Integrin $\alpha_{v} \beta_{3}$ protects breast cancer cells by activating MAPK pathway (Menendez et al., 2005). In addition, chemo-insensitive cancer cells cultured on specific ECM components reveal prolong cell cycle arrest after radiation treatment; providing time to repair radiation induced damage in DNA at cell-cycle check points (Bartek \& Lukas, 2001). Therefore, pre-formed spheroids embedded into or top of 3D matrix for cell invasion and metastasis study become apparent.

During the incorporation of spheroids into 3D ECM, certain essential conceptual requirements must be taken into serious consideration for successful establishment of spheroid based therapeutic screening model like spheroid size and geometry; which are mandatory prior to efficient scaling up spheroid system into preliminary drug screening models. The penetration of drug into spheroid is visualized by confocal screening or optical imaging technique; still lacks intense validation to their operating condition and high-throughput analysis of spheroids. The state-ofart of micro-fabrication techniques and conditions achieved to adopt cancer spheroid culture is highlighted in the following sections. 
Table 1

Preclinical metastases models: in vitro and in vivo.

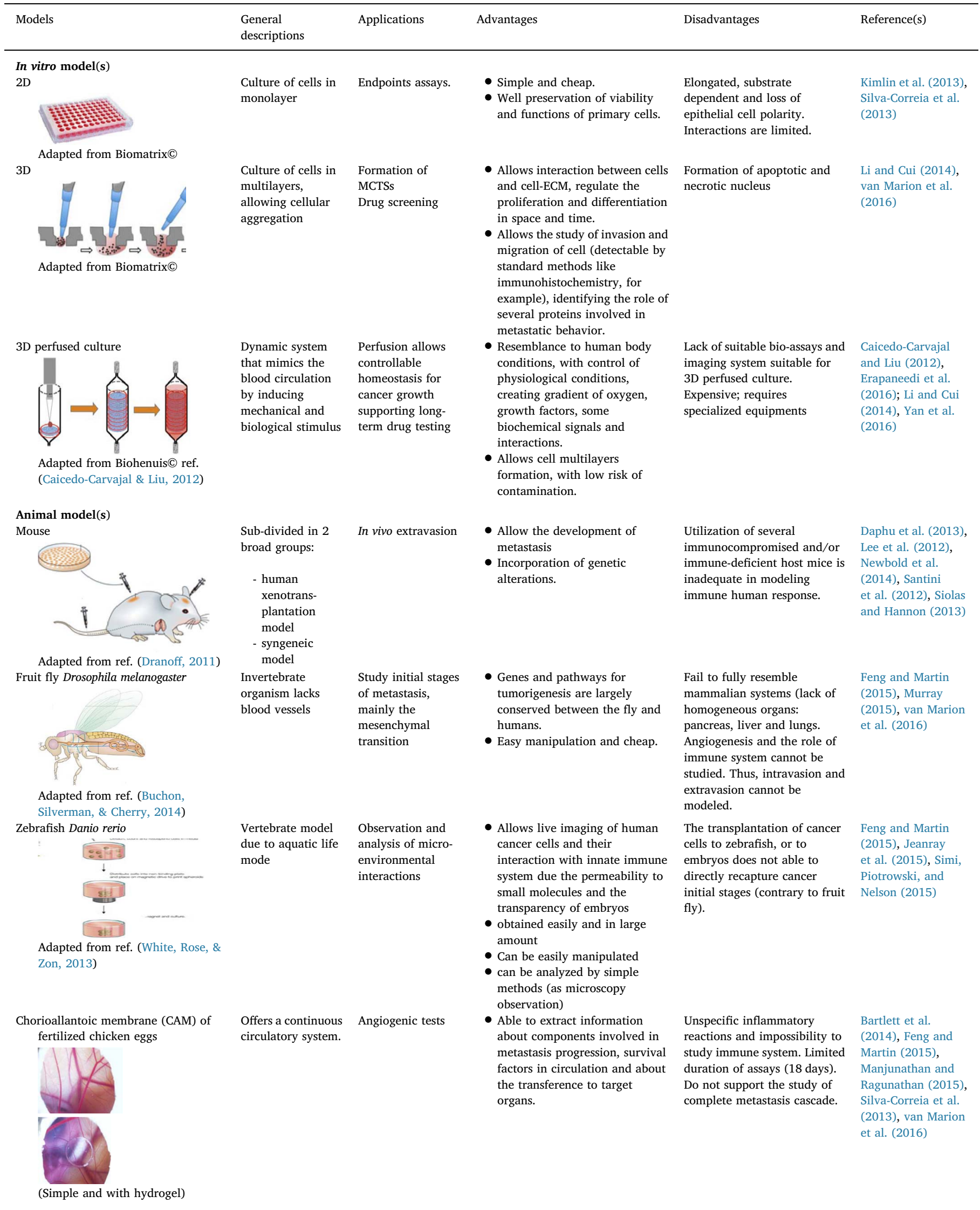


Table 2

Main characteristics of methods commonly used in culture of multicellular tumor spheroids.

\begin{tabular}{|c|c|c|c|c|}
\hline Methods & Applications & Advantages & Disadvantages & References \\
\hline $\begin{array}{l}\text { Hanging drop (pipetting manual, } \\
\text { array plate) }\end{array}$ & $\begin{array}{l}\text { To study tumor physiology, } \\
\text { metabolism, cellular } \\
\text { organization and development } \\
\text { - Co-culture of cells and study } \\
\text { cellular cross-talk } \\
\text { - Drug screening }\end{array}$ & $\begin{array}{l}\text { - Simple } \\
\text { Easy to scale-up and trace } \\
\text { MCTSs assembly } \\
\text { - Control of spheroid size by the } \\
\text { number of cells }\end{array}$ & $\begin{array}{l}\text { - Formation of } \\
\text { homogeneous MCTSs } \\
\text { is difficult, mainly in } \\
\text { size. } \\
\text { - Labor intensive and } \\
\text { present difficulties in } \\
\text { large-scale } \\
\text { production. } \\
\text { Long-term of culture is } \\
\text { difficult. }\end{array}$ & $\begin{array}{l}\text { Alemany-Ribes and Semino } \\
\text { (2014), Hsiao et al. (2012), } \\
\text { Khanna, Bhatt, and } \\
\text { Dwarakanath (2013), Mehta } \\
\text { et al. (2012), Thoma et al. } \\
\text { (2014), Vinci et al. (2012) }\end{array}$ \\
\hline $\begin{array}{l}\text { Soft agar liquid overlay } \\
\text { Adapted from ref. (Hickman et al., } \\
\text { 2014) }\end{array}$ & $\begin{array}{l}\text { Study interactions between } \\
\text { tumor cells and fibroblasts and } \\
\text { their role in tumor development }\end{array}$ & - Simple, ease in set-up & $\begin{array}{l}\text { - Formation of } \\
\text { homogeneous MCTSs } \\
\text { is difficult } \\
\text { - Limitations in mass } \\
\text { transference and cell } \\
\text { viability }\end{array}$ & $\begin{array}{l}\text { Alemany-Ribes and Semino } \\
\text { (2014), Hickman et al. (2014), } \\
\text { Khanna et al. (2013), Mehta } \\
\text { et al. (2012), Vinci et al. } \\
\text { (2012) }\end{array}$ \\
\hline $\begin{array}{l}\text { Rotative systems (spinner flask, roller } \\
\text { bottle, gyratory shaker, NASA } \\
\text { bioreactor) }\end{array}$ & $\begin{array}{l}\text { - Produce MCTSs in large scale } \\
\text { - Allow co-culture of cells }\end{array}$ & $\begin{array}{l}\text { Provide constant and dynamic } \\
\text { culture conditions } \\
\text { - Efficient for long-term cell } \\
\text { viability } \\
\text { - Low shear stress }\end{array}$ & $\begin{array}{l}\text { Formation of } \\
\text { homogeneous MCTSs } \\
\text { is difficult } \\
\text { - Not useful for drug } \\
\text { screening } \\
\text { - Expensive }\end{array}$ & $\begin{array}{l}\text { Alemany-Ribes and Semino } \\
\text { (2014), Khanna et al. (2013), } \\
\text { Vinci et al. (2012) }\end{array}$ \\
\hline \multicolumn{5}{|l|}{ Adapted from } \\
\hline $\begin{array}{l}\text { Microfabricated structures } \\
\text { (microchips and } \\
\text { microhydrophobic surfaces) }\end{array}$ & $\begin{array}{l}\text { - Perform 3D liver or stem cells } \\
\text { spheroids. } \\
\text { - Real-time imaging } \\
\text { - Drug screening. }\end{array}$ & $\begin{array}{l}\text { Homogeneous and controlled } \\
\text { MCTSs, both in size and } \\
\text { number. The MCTS size is } \\
\text { defined by pore size. }\end{array}$ & $\begin{array}{l}\text { - Require specialized } \\
\text { equipment. } \\
\text { - Low screening yield. }\end{array}$ & $\begin{array}{l}\text { Oliveira et al. (2014), Thoma } \\
\text { et al. (2014), van Marion et al. } \\
\text { (2016) }\end{array}$ \\
\hline \multicolumn{5}{|l|}{$\begin{array}{l}\text { Adapted from ref. (Oliveira et al., } \\
\text { 2014) }\end{array}$} \\
\hline $\begin{array}{l}\text { 3D Scaffolds } \\
\text { Adapted from 3DBiotek (C). }\end{array}$ & $\begin{array}{l}\text { Produce bioartificial tissues, } \\
\text { most effective for cancer drug/ } \\
\text { therapeutics screening. }\end{array}$ & $\begin{array}{l}\text { Provides a 3D support, } \\
\text { allowing the MCTs study using } \\
\text { several techniques }\end{array}$ & $\begin{array}{l}\text { Expensive, requires } \\
\text { specialized equipment } \\
\text { for to build scaffold. } \\
\text { Pooled screening } \\
\text { limited by low yield. }\end{array}$ & $\begin{array}{l}\text { Alemany-Ribes and Semino } \\
\text { (2014), Khanna et al. (2013), } \\
\text { Lozano et al. (2015) }\end{array}$ \\
\hline $\begin{array}{l}\text { Assembly (magnetic, paramagnetic, } \\
\text { micro-robotic, liquid-based) }\end{array}$ & $\begin{array}{l}\text { Incorporation of biomolecules } \\
\text { (proteins, nucleic acids, } \\
\text { carbohydrates, and lipids) to } \\
\text { form scalable functional } \\
\text { biomaterials for 3D cell culture }\end{array}$ & $\begin{array}{l}\text { Precision and reproducibility. } \\
\text { Allows the manipulation of } \\
\text { cells seeded in beads. } \\
\text { Cells remodel their } \\
\text { microenvironment and secrete } \\
\text { their own ECM. } \\
\text { - Co-culture of different cells. } \\
\text { - Rapid cell aggregation. }\end{array}$ & $\begin{array}{l}\text { - Require specialized } \\
\text { equipment and culture } \\
\text { conditions }\end{array}$ & $\begin{array}{l}\text { Alemany-Ribes and Semino } \\
\text { (2014), Asghar et al. (2015), } \\
\text { Khanna et al. (2013), Zhu et al. } \\
\text { (2016) }\end{array}$ \\
\hline $\begin{array}{l}\text { Adapted from Promega } @ \text {. } \\
\text { Bioprinting }\end{array}$ & - Develop complex 3Dstructure & • Allow designing geometry & - Difficult control over & Alemany-Ribes and Semino \\
\hline$x_{12}^{1}$ & $\begin{array}{l}\text { via a layer-by-layer approach, } \\
\text { pattern living cells, biological } \\
\text { macromolecules, and } \\
\text { biomaterials. } \\
\text { - Form complex 3D geometries } \\
\text { from computer-aided designs. }\end{array}$ & $\begin{array}{l}\text { aggregates; uniform number of } \\
\text { cells, size and composition } \\
\text { - Co-culture of different cells, it } \\
\text { is able to simultaneously } \\
\text { deposit live cells, growth } \\
\text { factors along with biomaterial } \\
\text { - Efficient, precise and rapid }\end{array}$ & $\begin{array}{l}\text { cell number and types } \\
\text { in individual droplets. } \\
\text { - Detected high stress } \\
\text { levels in cells. } \\
\text { - Require specialized } \\
\text { equipment, result } \\
\text { dependents of } \\
\text { operational technique. }\end{array}$ & $\begin{array}{l}\text { (2014), Khanna et al. (2013), } \\
\text { Knowlton et al. (2015), Lee } \\
\text { et al. (2014), Yue et al. (2015) }\end{array}$ \\
\hline
\end{tabular}




\subsection{Multicellular tumor spheroids (MCTs): biology, in vitro developmental strategies and statistical dissections for understanding cancer}

Recently, multi-cellular tumor spheroid (MCTS) model is gaining popularity because of its ability to strikingly mirror the three-dimensional cellular context of in vivo cancer and the extended flexibility to adapt mono-co-culture system based on therapeutic requirements. However, spheroid model is not a relevant tool for all malignant disease cases and even in one cancer type, varies with patho-physiological conditions (Friedrich, Ebner, \& Kunz-Schughart, 2007). For instance, non-solid cancers such as leukemia cells lack relevance of forming spheroid; however, their drug resistance characteristic is the phenomenon of cell adherent phenotype. With reference to melanoma, skin culture models are more appropriate to reflect tumorous behavior (Friedrich et al., 2007). Spheroids well serve as preclinical models of avascular metastases and solid tumors-provided the investigator is well acquainted with the relevant limitations. Moreover, the spheroid stroma resembles the intervascular micro-regions of sarcomas and carcinomas including gliomas and glioblastomas; make them rational choice by researchers. However, conduct trials of therapeutics of central nervous system (CNS) metastasis in laboratory using spheroid is difficult due to lack of reasonable blood-brain barrier (BBB) model in vitro (Bates, 2015). Size, low lipophilicity and sensitivity to multidrug transporter by most present therapeutics, are the limiting factors to cross BBB under physiological condition. Although, investigations like local invasiveness of glioblastomas, its growth pattern can be carried out using spheroids in association with appropriate ECM biomaterials such as collagen (Stein, Demuth, Mobley, Berens, \& Sander, 2007).

MCTSs are described as spherically symmetric aggregates of cells analogous to tissues, with no artificial substrate for cell attachment. A simple description of in vivo solid avascular tumor is included here for the realization of general readers. In avascular spheroid, a number of cells adhere to each other to form spherical cell mass; cells present at the periphery are actively cycling while residing adjacent to capillaries in situ (Kunz-Schughart, 1999). In contrast, the innermost region is quiescent necrotic zone. The concentric heterogeneous cell gradient in spheroid is representative of patho-physiological gradient and micrometastasis (break away of cancer cells from primary cancer sphere through blood or lymph into other body parts for development of new tumor) stage. When the critical size of cancer spheroid reaches beyond $500-600 \mu \mathrm{m}$, another secondary necrotic zone of $100-300 \mu \mathrm{m}$ is developed surrounding the quiescent necrotic zone (Friedrich et al., 2007). This is a viable rim of cells with limited oxygen, nutrients and restricted inward-outward diffusion; while maintaining intracellular homeostasis shortly till cell death. The sensitivity of tumor cells towards patho-physiological stress situation within multi-cellular tumor spheroid is dependent critically on their energy production under both anaerobic and aerobic condition.

Oncogene driven altered uncontrolled proliferation lacks adequate vascularization results in quick depletion of oxygen and nutrient in tumor cell mass causing hypoxia (i.e. lack of oxygen) (Eales, Hollinshead, \& Tennant, 2016). Average oxygen diffusion limit is up to $100-200 \mu \mathrm{m}$ in normal tissue; beyond this radius hypoxia occurs in cancer sphere. Hypoxia acts as stimulus in cancer cells triggering vascularization within tumor sphere by promoting angiogenesis with chaotic architecture leading to non-laminar flow of blood (Carmeliet \& Jain, 2000) at additional hypoxic regions. Within tumor spheroid, cells those reside in close proximity of blood supply have immense access of oxygen and nutrient and use aerobic oxidative phosphorylation supporting rapid proliferation (rapidly proliferating outermost region) (Martinez-Outschoorn, Peiris-Pages, Pestell, Sotgia, \& Lisanti, 2017). Cells far away from vasculature located at the center of spheroid are anabolic cell population committing alternative metabolic pathways like autophagy imparting adaptability to manage their energy need. Such an alteration in metabolism pathways within cancer microenvironment act as target for cancer treatment development. For more in-depth understanding of cancer metabolic signaling pathways we refer the readers to recent excellent reviews on cancer metabolism (Martinez-Outschoorn et al., 2017) and hypoxia (Eales et al., 2016). Though it perhaps impossible to state a common universal standard protocol of spheroid culture and investigation applicable under all experimental circumstances. The common disposable methods for MCTSs culture are: (i) hanging drop method (using conventional pipetting or microarrays/special well-plates); (ii) rotary cell culture system; (iii) culture into microfluidics chips; (iv) fabrication of the complex cellbiomaterial by bio-printing; and (v) self-assembly (without any external forces) (Erapaneedi, Belousov, Schafers, \& Kiefer, 2016; Gu et al., 2015; Hathaway et al., 2011). The main characteristics of each method are summarized in Table 2 (Bartlett et al., 2014; Zhu, Holmes, Glazer, \& Zhang, 2016).

MCTSs fabrication platforms are expected to measure physiologically active substances to satisfy four main requirements (Gong et al., 2015; Ota \& Miki, 2011); including: (i) good controllability during the formation of spheroids; (ii) allow culturing of formed spheroids for an extended time (i.e., longer than one day) with real-time morphological observations at any point; and (iii) incorporation of reagents such as dye or chemical stimulus to cells. These strategies involve in special non-adherent surface production. Non-adherent surfaces promote cellcell adhesions are most popular stationary phase for spheroid formation or maintenance. The existence of large repertoire of such materials is the proof of it and generally referred as microwell arrays. Polyethylene glycol (PEG) surfaces impart the resistance against the adhesion of both cells and proteins (Zhang, Desai, \& Ferrari, 1998), while support the bridging with micro-fluidic advancement. Alternatively, polydimethylsiloxane (PDMS) elastomers endure non-adhesive surface and spheroid formation along with the degree of freedom for lithography (Nakazawa, Izumi, \& Mori, 2009). Micro-contact printing of collagen adhesion motif on PEG-coated micro-wells acts as cell adhesion foci for spheroid assembly (Fukuda, Sakai, \& Nakazawa, 2006). The coating surface is not uniformly relevant for all materials; round-bottom wells treated with poly-hydroxyethyl methacrylate $(0.5 \mathrm{wt} \%)$ in ethanol $(95 \% \mathrm{v} / \mathrm{v})$ is advantageous (Ivascu \& Kubbies, 2006), while flat bottom wells coated with agarose results semi-solid, concave, non-adherent surface faciliating the formation of spheroids under the influence of micro-gravity (Friedrich, Seidel, Ebner, \& Kunz-Schughart, 2009). Coating process can be tailored for the advancement of spheroid development and to illustrate the hypoxia effect on disease advancement and vascularized models; with tremendous scope in fundamental and applied spheroid based research (Eglen \& Klein, 2017).

The resulting spheroids possess physiological cell-to-cell contacts, secrete their own ECM and develop nutrient, drug and oxygen transfer gradients similar to those found in physiological tissues. Moreover, the MCTSs can be studied continuously in hanging drops, or transferred to conventional cultured plates for further analysis or recovery (Hickman et al., 2014; Qiu et al., 2015). All basic analytical tools such as molecular analyses (DNA, RNA and protein) can be adapted well for 3D spheroids and allow comparing with that of monolayer culture if the analytical end point is a critical function of up or down regulation of a gene or a set of genes. Several literatures depict the genomic stability of multi-cellular spheroids, indicating the preservation of genomic profile of human malignant cells such as glioma in spheroid but lacks in monolayer (De Witt Hamer, Leenstra, Van Noorden, \& Zwinderman, 2009). Follow up strategies involve the employment of nanosilicon (Premnath, Tan, \& Venkatakrishnan, 2015), which is linked to nanoparticles or other nanostructures such as biosensors for cancer culture. The critical application of this is in "matrisome" research, i.e. the analysis of ECM and ECM-associated proteins for the development of proteomics-based methods coupled with bioinformatics to analyze the protein composition of ECM (Naba et al., 2012, 2014).

Statics are employed to further illustrate the mechanistic insight of solid tumor growth and development. The spatio-temporal model for avascular tumor growth narrates the size and shape change of tumor 
spheroid with experimental conditions and therapeutic exposure, which is attractive to model mathematically. Brown and Palmer proposes a probabilistic agent-based analysis technique based on time and size of tumor for ovarian cancer to anticipate early detection of unsuspected ovarian cancer and survival rate (Brown \& Palmer, 2009). The model postulates that ovarian tumors spend more than four years to develop (stage I and stage II), reaches stage III and/or stage IV in approximately one year before become clinically evident. The model then correlates the developmental time with the size of tumor; to obtain $50 \%$ sensitivity in tumor detection, the size of tumor needs to be $<1.3 \mathrm{~cm}$. For the reduction of serous ovarian cancer mortality rate by $50 \%$, early diagnostic screen needs to recognize tumor of $<0.5 \mathrm{~cm}$. Despite the difficulty in estimating the size of serous ovarian tumor with time; the stimulation corborrate with clinical observations of advanced stage ovarian tumor diameter, indicating "window of opportunity" of mathematical approach.

Shape or multidimensional profiling of spheroids are used to identify the molecular predictors of tumor phenotype by employing computed morphometric approach (Han et al., 2010). The use of consensus matrix and hierarchial clustering in predicting gene expression based spheroid architecture able to identify the stability of sub-population along with the shape and number of these sub-populations. This in silico approach is useful in predicting anti-cancer therapeutic efficacy in different sub-population of a typical cancer type.

The size of tumor spheroid changes upon growth, which is further regulated by distribution of diffusion factors including oxygen, glucose within the spheroid and is expressed with following equation (Byrne, 2010).

$\frac{d R}{d t}=\frac{1}{R^{2}} \int_{r=0}^{R} F(c) r^{2} d r$

Where function of $(F)$ growth factor concentrations $(C)$ such as oxygen or glucose regulate net cell growth, which in turn influences the spheroid size; $R(t)$ the change in radius of the spheroid with time. The distribution of growth factor within the spheroid is described as (Byrne, 2010):

$\frac{\partial c}{\partial t}=\frac{D}{r^{2}} \frac{\partial}{\partial r}\left(r^{2} \frac{\partial c}{\partial r}\right)-g(c, R)$

Where $D$ is the diffusion co-efficient of growth factor concentrations $(C)$ and $g(c, R)$ represents the local rate of consumption; together helpful to predict the physiological state of spheroid such as intra and inter cellular interactions, survival state of cells in spheroid. For instance, the threshold value of oxygen concentration in different region of spheroid delineates the physiological state of cells at that site; high oxygen concentration is the zone of cell proliferation, intermediate oxygen concentration is quiescence cell zone and very low oxygen concentration is necrotic zone. Initially, an exponential growth phase is encountered by spheroid antiquated by linear fugitive phase with constant value of outer proliferating rim till the spheroid reach the equilibrium size, where the death and growth of spheroid cells reached balance. The agreement between experimental reports and mathematical dynamic models contribute a realistic insight of disease progression and effect of regulator distribution.

However, this simple model encounters limited applicability to the consideration of a single cell population ignore stochastic effects of different emerging clonal sub-population and involvement of multiple metabolite compared to single (Pantel \& Brakenhoff, 2004). Broad literature range on extension and modification of original sphere model is too enormous to be discussed herein. Briefly, the initial linear assumption is replaced by non-linear equation proposed by Cristini and colleagues relating the irregular shape of the spheres (Cristini, Lowengrub, \& Nie, 2003). They propose compact shape of highly vascularized tumor compared to the fragmented fingers under limited nutrients.
Mathematical models can also be used as statistical tool to develop new therapies including evaluation of response of those of existing including chemotherapy and radiotherapy. The response of a spheroid towards the treatment of a drug is expressed as (Mehta, Hsiao, Ingram, Luker, \& Takayama, 2012; Ward \& King, 2003):

$\frac{\partial n}{\partial t}+\frac{1}{r^{2}} \frac{\partial\left(r^{2} v n\right)}{\partial r}=\left[K_{m}(c)-k_{d}(c)-K G\left(k_{m}(c)\right) f(w)\right]_{n}$

Where live cell density (cells/unit volume) $=n$, concentration of nutrients $=c$, live cell velocity $=v$ and concentration of drug $=w$ are dependent variables. $r$ represents radius of spheroids. In Eq. (3), the rate of change in numbers of cells per unit volume $(n)$ is obtained from the discrepancy between the rate of birth $\left(\kappa_{m}(c)\right)$ and death $\left(\kappa_{d}(c)\right)$; where death is caused naturally or in response to drug at a rate of $K G\left(\kappa_{m}(c) f\right.$ $(w))$. Constant $K$ represents the maximum achievable drug induced cell death. The value of $\mathrm{K}$ can be used to predict patient-specific outcome of specific therapeutics; beneficial for the development of personalized anti-cancer therapeutics.

$\frac{\partial c}{\partial t}+\frac{1}{r^{2}} \frac{\partial\left(r^{2} v c\right)}{\partial r}=\frac{D}{r^{2}} \frac{\partial}{\partial r}\left(r^{2} \frac{\partial c}{\partial r}\right)-\beta \kappa_{m}(c) n$

Eq. (4) depicts the nutrient diffusion by Fick's law. It permits to model diffusion mediated transportation in nonhomogenous media.

$\frac{1}{r^{2}} \frac{\partial\left(r^{2} v\right)}{\partial r}=\left[V_{L} \kappa_{m}(c)-\left(V_{L}-V_{D}\right)\left\{\kappa_{d}(c)+K G\left(\kappa_{m}(c)\right) f(w)\right\}\right]_{n}$

Eq. (5) represents the change in volume of spheroid measured by subtracting the volume generated by birth $\left(V_{L} \kappa_{m}(c) n\right)$ from that of losing by death $\left.\left(\left(V_{L}-V_{D}\right)\left\{\kappa_{d}(c)+K G\left(\kappa_{m}(c)\right) f(w)\right\}\right]_{n}\right)$, where $\left(V_{L} n\right)$ state living cell volume fraction, $\left(1-V_{L} n\right)$ state necrotic material volume fraction and $V_{L}$ and $V_{D}$ are inverse phenomena (volume/cell) of a live and dead cell.

Using these mathematical frameworks, the treatment response of a tumor spheroid can be stimulated. When applied to a non-small cell lung cancer, the stimulations qualitatively reproduce time dependent morphogenesis of tumor in agreement with growth curves of patient (Lecca \& Morpurgo, 2012). Non-linear models of cancer growth are more realistic representation of physiological cancer growth; help in determining the administration schedule and therapy duration in clinical practice.

The development of physiologically relevant in silico model is one of the key approach in obtaining personalized therapy and is anticipated to reveal predictive and prognostic biomarkers with low cost and in less time.

\section{Next generation in vitro modeling of cancer using biomaterials}

Spheroids in cancer biology have already been envisioned as tool to study the role of adhesion molecules (such as E-cadherin, Kallikreinrelated peptidase and integrin) or considered as organoid to study drug sensitivity (Fennema, Rivron, Rouwkema, van Blitterswijk, \& de Boer, 2013). With the advancement in sprouted innovative approaches imparting the controllability of tumor size (on a micrometer scale), reproduces the desired native microenvironment of tumor. However, the in vivo bi-directional interaction in terms of elasticity, rigidity between cultured cells and surrounding niche is yet to achieve. Natural biomaterials such as collagen gel (Sabeh, Shimizu-Hirota, \& Weiss, 2009) or laminin-rich ECM (Kleinman \& Martin, 2005) possess micro or nano fibril dimension of native ECM, therefore, used by cancer researchers for past two decades. But these biomaterials often possess residual growth factors or undefined substances and suffer from batch to batch variation. Hence, as advancement in cancer research, reproducible 3D cell-culture system is desirable. Polyacrylamide gels are most exploited to elaborate the putative role of matrix stiffness on tumor development and progression (Pathak \& Kumar, 2012). To unwind the underlying mechanism of matrix induced mechanical cue, composition and 
1
A

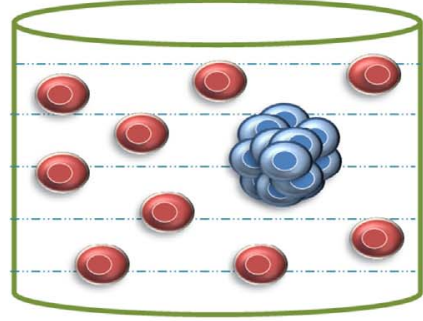

B

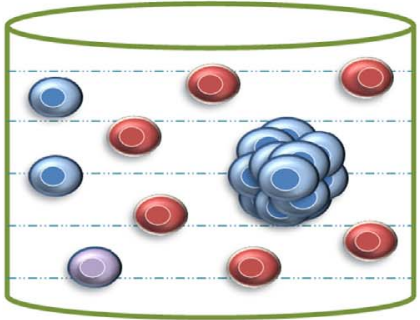

C

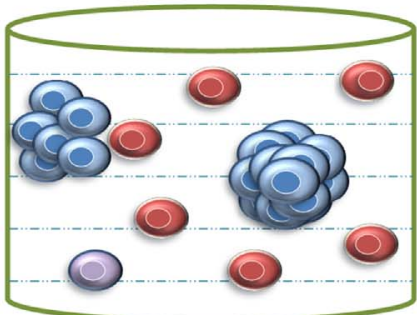

2

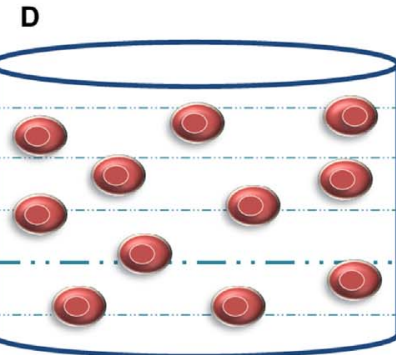

E

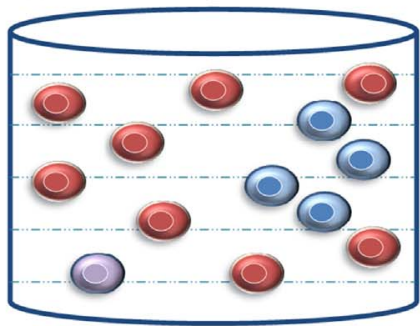

$\mathbf{F}$

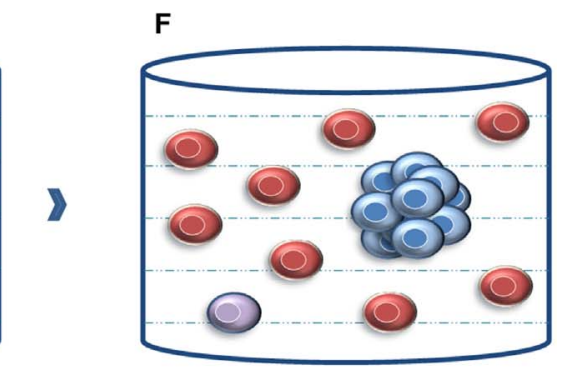

\section{$\sqrt{10}$}

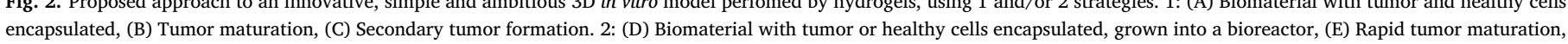
(F) Secondary tumor formation.

architecture independent stiff interpenetrating polymer network is created using reconstituted basement membrane and alginate (Chaudhuri et al., 2014); where stiffness is regulated by ionic crosslinking of alginate without the change in polymer concentration. Cells sense the enhanced stiffness through $\beta 4$ integrin and PI3K pathway, results in loss of apicobasal polarity and basement membrane invasion. The ability to regulate the mechanical properties of biomaterials permits us to investigate if the different population of tumor cells in 3D prefer hard or soft environment. The application of tissue engineering concepts in tumor research focus on designing of scaffolds or hydrogels mimicking the feature of ECM (Fennema et al., 2013).

Natural biomaterials obtained from the mammalian ECM, therefore, are gaining attention namely hyaluronic acid and fibrin, have good control over quantity of ECM proteins and growth factors with low immunogenicity (Chwalek, Bray, \& Werner, 2014; Koch et al., 2014; Yue et al., 2015). Synthetic biomaterials, such as polyethylene glycol (PEG), copolymers developed of PEG with poly(L-lactide) (PLLA) and poly(D,L-lactide-co-glycolide) (PLGA) are also favored due to their interesting proteolytic degradability, cell adhesion site and matrix stiffness; able to support the growth of cancer cells and tumor angiogenesis, controlling myriad parameters etc. (Fuller \& Howell, 2014; Ma et al., 2012). Synthetic biomaterials also offer ease in chemical modifications, selective regulation on biochemical and mechanical properties (Chwalek et al., 2014; Ma et al., 2012). Recenet advancement in bioengineering enable the grafting of motifs like arginine-glycine-aspartic acid (RGD) in synthetic polymers to explore the role of tumor cell integrin in angiogenic signaling (Gill et al., 2012). Commercially available polysaccharide Gellan gum is printed as sacrificial template within fibroblast encapsulating hydrogels for vasculature (Miller et al., 2012). The carbohydrate fibers dissolves with time using medium perfusion; leaving behind the void space for subsequent seeding and growth of endothelial cells - serves as potential 3D matrix in cancer cell research. To obtain precise spatiotemporal arrangement of cells within 3D microenvironment, microfluidics and photo-patterning techniques are used.

Micro-fluidic vascular cancer model obtained so far is grouped into two categories; (i) micro-fabricated molds containing parallel microfluidic channels (Nguyen et al., 2013) and (ii) vascular structures completely embedded in 3D matrix (Miller et al., 2012). Micro-fabricated mold is obtained by embedding micro-channels within collagen hydrogel, facilitating the real-time quantification of tumor relevant hydrodynamic stresses using microparticle image velocimetry (Buchanan et al., 2014). The vascular structure is generated using human-iPSC derived cells cultured in cardiac ECM along with cardiac muscle and solid tumor into an integrated physiological system (Moya, Tran, \& George, 2013). Metastatic invasion is incorporated at the tumor vascular interface, designed using microfluidics; compromised of two independent channels seeded with tumor and endothelial cells and connected by type I collagen hydrogel ECM (Zervantonakis et al., 2012). The "tumor on chip" supports live imaging, manipulation of micro-environmental factors and measurement of endothelial barrier. The conceptual progresses emerge the hallmark of cancer research by including reprogrammed energy metabolism, recruiting ostensibly normal cells and immune cells in acquisition of in vivo tumor. The 
insight is expected to affect the development of new cancer therapy.

Bio-printing technology is being applied to generate methacrylategellan gum (Me-GG) based 3D cell-matrix constructs with controlled architectures for several tissue engineering applications (Billiet, Gevaert, De Schryver, Cornelissen, \& Dubruel, 2014; Hickman et al., 2014; Silva-Correia et al., 2012; Yue et al., 2015). Combining the principles of tissue engineering with microfluidics; "organ-on-chip" is achieved, which mimics physiological environment and interactions allowing the quantitative measurements of circulating tumor cells, extravasation and micro-metastasis (Carvalho et al., 2015). Bioprinting also allows fabricating micro-vessel models as microfluidic channels to capture the native angiogenesis process within MCTSs more accurately, as illustrated in Fig. 2. The choice of bio-inks for tumor modeling is critical, taking into consideration its printability, biocompatibility, cross-linking agents, viability of printed cells etc. and well discussed elsewhere (Knowlton, Onal, Yu, Zhao, \& Tasoglu, 2015; Zhang et al., 2016). Me-GG solution mixed with chondrocyte cells is successfully bioprinted into multiple layered network structures without losing cellular viability (Schuurman et al., 2013). Me-GG also imparts thermal gelation, which aids in retaining the shape of printed constructs (Schuurman et al., 2013; Song, Park, \& Gerecht, 2014). The viability of hepato-carcinoma cells within this printed gels are directly related with needle shape and printing pressure (Billiet et al., 2014). Usually two types of cross-linking strategies are adopted in bio-inks, physical and ionic crosslinking; both of which can be applied for Me-GG and referred as iME-GG (ionic) or phMe-GG (photo-crosslinked) (Silva-Correia et al., 2013). The approaches are likely to be useful in achieving the functional bio-printed cancer tissue in near future.

\section{Future directions}

The present review revisits, refines and extends up to the conceptual understanding of the available engineering approaches and in silico models of in vitro cancer. The acquired models have stood the test of time - further refinement is definitely to be foreseen in future; contributing towards the conceptual progress from past decades. Despite the remarkable substantial journey from 2D to 3D, the limitations such as sophisticated animal models well eliciting the large tumor heterogeneity like human cancer, advanced metastasis models including the development of steps of metastatic cascade and incorporation of fully functional immune system still exists.

To restore complete native microenvironment, in vitro systems are necessary to define with precision. Many strategies are planned, but the secret possibility resides in simplicity of ideas. The replacement of in vivo animal models by 3D culture models in terms of successful reproduction of complete colossal complexity of cancer biology and metastases - is not projected yet. But breaking down of pathological and physiological complexity into amenable number of experimental interactions in 3D is envisioned; serving as drug response platform, investigation of biomarkers, chemotherapeutic resistance and alternative combinational approach to overcome the resistance approach is possible to mirror using 3D models.

The architecture theory of 'form follows function' appears be true in tumor organoid culture; bridging the gap between cancer genetics and patient trials, augment cell-line- and xenograft-mediated drug response studies (van de Wetering et al., 2015). This initiative emphasizes MCTSs encapsulation within suitable biomaterials, holds great potential. For scaffold based approaches, the type of the materials used should be carefully selected keeping in mind the nature of drugs to be screened (Nugraha et al., 2011) or the purpose of the study. For instance, horseradish peroxidase crosslinked silk fibroin hydrogel system suppresses angiogenesis and tumor both in vitro and in vivo (Yan et al., 2016); therefore, not applicable for tumor modeling study but suitable for anti-cancer therapeutics. Self-assembled peptide hydrogels obtained by entanglement of fibrillary structure through supramolecular interactions is also attractive for in situ gelation and micro- fluidic chips
(Huang, Ding, Sun, \& Nguyen, 2013). However, long-term stability of such material is needed to be investigated.

The revolution of cancer genetics and proteomics is collection of "big data". Data generated using biomaterial library, patient care and scientific research help to have closer look into multi-dimensional cancer map; allow us to correlate gene expression with cellular pathways. The analysis of cellular pathways of cancer in detail is needed, which not only gives more insight in the molecular processes of metastasis but can be applied in improvement of existing models; unwinding new targets of disease progression. Specific disease relevance along with the processing efficacy needs to be evaluated to promote the "pay for performance" concept, while reduce the cost of health care. In this regard, 3D metastasis models developed further turned into human tumor platform as personalized medicine, for evaluating tumor progression of individual patients, using their own tumor cells. There is the hope of using great personalized models in prospection of successful clinical result (high-throughput screening).

\section{Executive summary}

The constraints of existing models are now well understood. Despite advances in biomedical engineering and medicine, cancer still remains a major health issue. Tumor spheroid is no doubt a versatile and potential biomimicry tool in cancer research and therapeutic development; but not enough to model the complex biology of cancer, in particular the metastasis cascade. Hence, involvement of microfabrication process and computer-based algorithms are needed to capture the aspects of metastasis more precisely than yet realized. Engineering humanized organ model in laboratory animal is an alternative approach to in vitro culture system, but co-implantation of biomaterials and spheroid culture as key component of the system; recognizing the inescapable role of biomaterials in 3D cancer research. Furthur, given the acknowledgement that tumor microenvironment is the predominant shelter of surviving tumor cell population following chemotherapy; recapitulate it using biomaterials may unwind the underlying insight of ECM mediated drug resistance. We anticipate biomaterial based advanced cancer spheroid are expected to translate better personalized patient-specific therapeutic interventions.

\section{Conflict of interest statement}

The authors declare that there is no conflicts of interest.

\section{Acknowledgments}

The authors are thankful to European Union (Horizon 2020) funded project FoReCaST (No. 668983), the FCT fellowship to J. Silva-Correia (Grant No. SFRH/BPD/100590/2014), distinctions to J.M.O. under the Investigator FCT program (IF/00423/2012) and V.M.C. under the Investigator FCT program (IF/01214/2014) for supporting this work financially.

\section{References}

Alemany-Ribes, M., \& Semino, C. E. (2014). Bioengineering 3D environments for cancer models. Advanced Drug Delivery Reviews, 79-80, 40-49.

Amann, A., Zwierzina, M., Gamerith, G., Bitsche, M., Huber, J. M., Vogel, G. F., Zwierzina, H. (2014). Development of an innovative 3D cell culture system to study tumour-stroma interactions in non-small cell lung cancer cells. PLoS One, 9, e92511.

Amit, M., Na'ara, S., \& Gil, Z. (2016). Mechanisms of cancer dissemination along nerves. Nature Reviews. Cancer, 16, 399-408.

Asghar, W., El Assal, R., Shafiee, H., Pitteri, S., Paulmurugan, R., \& Demirci, U. (2015). Engineering cancer microenvironments for in vitro 3-D tumor models. Materials Today, 18, 539-553.

Azarin, S. M., Yi, J., Gower, R. M., Aguado, B. A., Sullivan, M. E., Goodman, A. G., ... Shea, L. D. (2015). In vivo capture and label-free detection of early metastatic cells. Nature Communications, 6, 8094.

Barcellos-Hoff, M. H., Lyden, D., \& Wang, T. C. (2013). The evolution of the cancer niche during multistage carcinogenesis. Nature Reviews. Cancer, 13, 511-518. 
Bartek, J., \& Lukas, J. (2001). Mammalian G1- and S-phase checkpoints in response to DNA damage. Current Opinion in Cell Biology, 13, 738-747.

Bartlett, R., Everett, W., Lim, S., Natasha, G., Loizidou, M., Jell, G., Tan, A., \& Seifalian, A. M. (2014). Personalized in vitro cancer modeling - Fantasy or reality? Translational Oncology, 7, 657-664.

Bates, S. E. (2015). Central nervous system metastasis from breast cancer. The Oncologist, $20,3-4$.

Begley, C. G., \& Ellis, L. M. (2012). Drug development: Raise standards for preclinical cancer research. Nature, 483, 531-533.

Billiet, T., Gevaert, E., De Schryver, T., Cornelissen, M., \& Dubruel, P. (2014). The 3D printing of gelatin methacrylamide cell-laden tissue-engineered constructs with high cell viability. Biomaterials, 35, 49-62.

Bremnes, R. M., Donnem, T., Al-Saad, S., Al-Shibli, K., Andersen, S., Sirera, R., ... Busund, L. T. (2011). The role of tumor stroma in cancer progression and prognosis: Emphasis on carcinoma-associated fibroblasts and non-small cell lung cancer. Journal of Thoracic Oncology, 6, 209-217.

Brown, P. O., \& Palmer, C. (2009). The preclinical natural history of serous ovarian cancer: Defining the target for early detection. PLOS Medicine, 6, e1000114.

Buchanan, C. F., Voigt, E. E., Szot, C. S., Freeman, J. W., Vlachos, P. P., \& Rylander, M. N. (2014). Three-dimensional microfluidic collagen hydrogels for investigating flowmediated tumor-endothelial signaling and vascular organization. Tissue Engineering. Part C, Methods, 20, 64-75.

Buchon, N., Silverman, N., \& Cherry, S. (2014). Immunity in Drosophila melanogaster-from microbial recognition to whole-organism physiology. Nature Reviews. Immunology, 14, 796-810.

Byrne, H. M. (2010). Dissecting cancer through mathematics: From the cell to the animal model. Nature Reviews. Cancer, 10, 221-230.

Caicedo-Carvajal, C. E., \& Liu, Q. (2012, Spring). Using a novel 3D perfusion bioreactor to culture $\beta$-actin-RFP reporter osteosarcoma $\mid$ biowire.

Carmeliet, P., \& Jain, R. K. (2000). Angiogenesis in cancer and other diseases. Nature, 407, 249-257.

Carvalho, M. R., Lima, D., Reis, R. L., Correlo, V. M., \& Oliveira, J. M. (2015). Evaluating biomaterial- and microfluidic-based 3D tumor models. Trends in Biotechnology, 33, 667-678.

Chambers, A. F., Groom, A. C., \& MacDonald, I. C. (2002). Dissemination and growth of cancer cells in metastatic sites. Nature Reviews. Cancer, 2, 563-572.

Chaudhuri, O., Koshy, S. T., Branco da Cunha, C., Shin, J. W., Verbeke, C. S., Allison, K. H., \& Mooney, D. J. (2014). Extracellular matrix stiffness and composition jointly regulate the induction of malignant phenotypes in mammary epithelium. Nature Materials, 13, 970-978.

Chwalek, K., Bray, L. J., \& Werner, C. (2014). Tissue-engineered 3D tumor angiogenesis models: Potential technologies for anti-cancer drug discovery. Advanced Drug Delivery Reviews, 79-80, 30-39.

Colacino, J. A. (2016). 3D human tissue culture: Modeling environmental effects on the stem cell epigenome. Epigenomics, 8, 1453-1457.

Correia, A. L., \& Bissell, M. J. (2012). The tumor microenvironment is a dominant force in multidrug resistance. Drug Resistance Updates, 15, 39-49.

Costa, E. C., Moreira, A. F., de Melo-Diogo, D., Gaspar, V. M., Carvalho, M. P., \& Correia, I. J. (2016). 3D tumor spheroids: An overview on the tools and techniques used for their analysis. Biotechnology Advances, 34, 1427-1441.

Cristini, V., Lowengrub, J., \& Nie, Q. (2003). Nonlinear simulation of tumor growth. Journal of Mathematical Biology, 46, 191-224.

Cuperlovic-Culf, M., Culf, A. S., Touaibia, M., \& Lefort, N. (2012). Targeting the latest hallmark of cancer: Another attempt at 'magic bullet' drugs targeting cancers' metabolic phenotype. Future Oncology, 8, 1315-1330.

Daphu, I., Sundstrom, T., Horn, S., Huszthy, P. C., Niclou, S. P., Sakariassen, P. O., ... Thorsen, F. (2013). In vivo animal models for studying brain metastasis: Value and limitations. Clinical \& Experimental Metastasis, 30, 695-710.

De Witt Hamer, P. C., Leenstra, S., Van Noorden, C. J., \& Zwinderman, A. H. (2009). Organotypic glioma spheroids for screening of experimental therapies: How many spheroids and sections are required? Cytometry. Part A, 75, 528-534.

Desoize, B., \& Jardillier, J. (2000). Multicellular resistance: A paradigm for clinical resistance? Critical Reviews in Oncology/Hematology, 36, 193-207.

Dranoff, G. (2011). Experimental mouse tumour models: What can be learnt about human cancer immunology? Nature Reviews. Immunology, 12, 61-66.

Dubessy, C., Merlin, J. M., Marchal, C., \& Guillemin, F. (2000). Spheroids in radiobiology and photodynamic therapy. Critical Reviews in Oncology/Hematology, 36, 179-192.

Eales, K. L., Hollinshead, K. E., \& Tennant, D. A. (2016). Hypoxia and metabolic adaptation of cancer cells. Oncogene, 5, e190.

Eglen, R. M., \& Klein, J. L. (2017). Three-dimensional cell culture: A rapidly emerging approach to cellular science and drug discovery. SLAS Discovery, 22, 453-455.

Engel, A. M., Svane, I. M., Mouritsen, S., Rygaard, J., Clausen, J., \& Werdelin, O. (1996). Methylcholanthrene-induced sarcomas in nude mice have short induction times and relatively low levels of surface MHC class I expression. APMIS, 104, 629-639.

Erapaneedi, R., Belousov, V. V., Schafers, M., \& Kiefer, F. (2016). A novel family of fluorescent hypoxia sensors reveal strong heterogeneity in tumor hypoxia at the cellular level. The EMBO Journal, 35, 102-113.

Fang, Y., \& Eglen, R. M. (2017). Three-dimensional cell cultures in drug discovery and development. SLAS Discovery, 22, 456-472 (2472555217696795).

Feng, Y., \& Martin, P. (2015). Imaging innate immune responses at tumour initiation: New insights from fish and flies. Nature Reviews. Cancer, 15, 556-562.

Fennema, E., Rivron, N., Rouwkema, J., van Blitterswijk, C., \& de Boer, J. (2013). Spheroid culture as a tool for creating 3D complex tissues. Trends in Biotechnology, 31, 108-115.

Friedrich, J., Ebner, R., \& Kunz-Schughart, L. A. (2007). Experimental anti-tumor therapy in 3-D: Spheroids-Old hat or new challenge? International Journal of Radiation Biology,
$83,849-871$

Friedrich, J., Seidel, C., Ebner, R., \& Kunz-Schughart, L. A. (2009). Spheroid-based drug screen: Considerations and practical approach. Nature Protocols, 4, 309-324.

Fukuda, J., Sakai, Y., \& Nakazawa, K. (2006). Novel hepatocyte culture system developed using microfabrication and collagen/polyethylene glycol microcontact printing. Biomaterials, 27, 1061-1070.

Fuller, E. S., \& Howell, V. M. (2014). Culture models to define key mediators of cancer matrix remodeling. Frontiers in Oncology, 4, 57.

Gill, B. J., Gibbons, D. L., Roudsari, L. C., Saik, J. E., Rizvi, Z. H., Roybal, J. D., ... West, J. L. (2012). A synthetic matrix with independently tunable biochemistry and mechanical properties to study epithelial morphogenesis and EMT in a lung adenocarcinoma model. Cancer Research, 72, 6013-6023.

Giuliano, M., Giordano, A., Jackson, S., De Giorgi, U., Mego, M., Cohen, E. N., ... Cristofanilli, M. (2014). Circulating tumor cells as early predictors of metastatic spread in breast cancer patients with limited metastatic dissemination. Breast Cancer Research, 16, 440.

Gong, X., Lin, C., Cheng, J., Su, J., Zhao, H., Liu, T., ... Zhao, P. (2015). Generation of multicellular tumor spheroids with microwell-based agarose scaffolds for drug testing. PLoS One, 10, e0130348.

Gottfried, E., Kunz-Schughart, L. A., Andreesen, R., \& Kreutz, M. (2006). Brave little world: Spheroids as an in vitro model to study tumor-immune-cell interactions. Cell Cycle, 5, 691-695.

Gu, Y., Ju, C., Li, Y., Shang, Z., Wu, Y., Jia, Y., \& Niu, Y. (2015). Detection of circulating tumor cells in prostate cancer based on carboxylated graphene oxide modified light addressable potentiometric sensor. Biosensors and Bioelectronics, 66, 24-31.

Han, J., Chang, H., Giricz, O., Lee, G. Y., Baehner, F. L., Gray, J. W., ... Parvin, B. (2010). Molecular predictors of 3D morphogenesis by breast cancer cell lines in 3D culture. PLoS Computational Biology, 6, e1000684.

Hathaway, H. J., Butler, K. S., Adolphi, N. L., Lovato, D. M., Belfon, R., Fegan, D., ... Flynn, E. R. (2011). Detection of breast cancer cells using targeted magnetic nanoparticles and ultra-sensitive magnetic field sensors. Breast Cancer Research, 13, R108.

Hensel, J. A., Flaig, T. W., \& Theodorescu, D. (2013). Clinical opportunities and challenges in targeting tumour dormancy. Nature Reviews. Clinical Oncology, 10, 41-51.

Hibberd, C., Cossigny, D. A., \& Quan, G. M. (2013). Animal cancer models of skeletal metastasis. Cancer Growth Metastasis, 6, 23-34.

Hickman, J. A., Graeser, R., de Hoogt, R., Vidic, S., Brito, C., Gutekunst, M., ... Consortium, I. P. (2014). Three-dimensional models of cancer for pharmacology and cancer cell biology: Capturing tumor complexity in vitro/ex vivo. Biotechnology Journal, 9, 1115-1128.

Hidalgo, M., Bruckheimer, E., Rajeshkumar, N. V., Garrido-Laguna, I., De Oliveira, E., Rubio-Viqueira, B., ... Sidransky, D. (2011). A pilot clinical study of treatment guided by personalized tumorgrafts in patients with advanced cancer. Molecular Cancer Therapeutics, 10, 1311-1316.

Hoshino, A., Costa-Silva, B., Shen, T. L., Rodrigues, G., Hashimoto, A., Tesic Mark, M., Lyden, D. (2015). Tumour exosome integrins determine organotropic metastasis. Nature, 527, 329-335.

Hsiao, A. Y., Tung, Y. C., Qu, X., Patel, L. R., Pienta, K. J., \& Takayama, S. (2012). 384 hanging drop arrays give excellent Z-factors and allow versatile formation of coculture spheroids. Biotechnology and Bioengineering, 109, 1293-1304.

Huang, H., Ding, Y., Sun, X. S., \& Nguyen, T. A. (2013). Peptide hydrogelation and cell encapsulation for 3D culture of MCF-7 breast cancer cells. PLoS One, 8, e59482.

Ivascu, A., \& Kubbies, M. (2006). Rapid generation of single-tumor spheroids for highthroughput cell function and toxicity analysis. Journal of Biomolecular Screening, 11, 922-932.

Jeanray, N., Maree, R., Pruvot, B., Stern, O., Geurts, P., Wehenkel, L., \& Muller, M. (2015). Phenotype classification of zebrafish embryos by supervised learning. PLoS One, 10, e0116989.

Joyce, J. A., \& Pollard, J. W. (2009). Microenvironmental regulation of metastasis. Nature Reviews Cancer, 9, 239-252.

Khanna, S., Bhatt, A. N., \& Dwarakanath, B. S. (2013). Multicellular spheroid: 3-D tissue culture model for cancer research. Animal biotechnology: Models in discovery and translation (pp. 195-210).

Khanna, C., \& Hunter, K. (2005). Modeling metastasis in vivo. Carcinogenesis, 26, $513-523$.

Kimlin, L. C., Casagrande, G., \& Virador, V. M. (2013). In vitro three-dimensional (3D) models in cancer research: An update. Molecular Carcinogenesis, 52, 167-182.

Kleinman, H. K., \& Martin, G. R. (2005). Matrigel: Basement membrane matrix with biological activity. Seminars in Cancer Biology, 15, 378-386.

Knowlton, S., Onal, S., Yu, C. H., Zhao, J. J., \& Tasoglu, S. (2015). Bioprinting for cancer research. Trends in Biotechnology, 33, 504-513.

Koch, A., Saran, S., Tran, D. D., Klebba-Farber, S., Thiesler, H., Sewald, K., ... Tamura, T. (2014). Murine precision-cut liver slices (PCLS): A new tool for studying tumor microenvironments and cell signaling ex vivo. Cell Communication and Signaling: CCS, $12,73$.

Kuchnio, A., Moens, S., Bruning, U., Kuchnio, K., Cruys, B., Thienpont, B., ... Carmeliet, P. (2015). The cancer cell oxygen sensor PHD2 promotes metastasis via activation of cancer-associated fibroblasts. Cell Reports, 12, 992-1005.

Kunz-Schughart, L. A. (1999). Multicellular tumor spheroids: Intermediates between monolayer culture and in vivo tumor. Cell Biology International, 23, 157-161.

Kuzet, S. E., \& Gaggioli, C. (2016). Fibroblast activation in cancer: When seed fertilizes soil. Cell and Tissue Research, 365, 607-619.

Lecca, P., \& Morpurgo, D. (2012). Modelling non-homogeneous stochastic reaction-diffusion systems: The case study of gemcitabine-treated non-small cell lung cancer growth. BMC Bioinformatics, 13(Suppl. 14), S14.

Lee, B. R., Hwang, J. W., Choi, Y. Y., Wong, S. F., Hwang, Y. H., Lee, D. Y., \& Lee, S. H. (2012). In situ formation and collagen-alginate composite encapsulation of 
pancreatic islet spheroids. Biomaterials, 33, 837-845.

Lee, V. K., Kim, D. Y., Ngo, H., Lee, Y., Seo, L., Yoo, S. S., ... Dai, G. (2014). Creating perfused functional vascular channels using 3D bio-printing technology. Biomaterials, 35, 8092-8102.

Li, G. (2015). Patient-derived xenograft models for oncology drug discovery. Journal of Cancer Metastasis and Treatment, 1, 8-15.

Li, Z., \& Cui, Z. (2014). Three-dimensional perfused cell culture. Biotechnology Advances, 32, 243-254.

Loessner, D., Little, J. P., Pettet, G. J., \& Hutmacher, D. W. (2013). A multiscale road map of cancer spheroids-Incorporating experimental and mathematical modelling to understand cancer progression. Journal of Cell Science, 126, 2761-2771.

Lohr, J. G., Adalsteinsson, V. A., Cibulskis, K., Choudhury, A. D., Rosenberg, M., CruzGordillo, P., ... Love, J. C. (2014). Whole-exome sequencing of circulating tumor cells provides a window into metastatic prostate cancer. Nature Biotechnology, 32, 479-484.

Lozano, R., Stevens, L., Thompson, B. C., Gilmore, K. J., Gorkin, R., III, Stewart, E. M., Wallace, G. G. (2015). 3D printing of layered brain-like structures using peptide modified gellan gum substrates. Biomaterials, 67, 264-273.

Ma, H. L., Jiang, Q., Han, S., Wu, Y., Cui Tomshine, J., Wang, D., ... Liang, X. J. (2012). Multicellular tumor spheroids as an in vivo-like tumor model for three-dimensional imaging of chemotherapeutic and nano material cellular penetration. Molecular Imaging, 11, 487-498.

Manjunathan, R., \& Ragunathan, M. (2015). Chicken chorioallantoic membrane as a reliable model to evaluate osteosarcoma-an experimental approach using SaOS2 cell line. Biological Procedures Online, 17, 10.

Martinez-Outschoorn, U. E., Peiris-Pages, M., Pestell, R. G., Sotgia, F., \& Lisanti, M. P. (2017). Cancer metabolism: A therapeutic perspective. Nature Reviews. Clinical Oncology, 14, 11-31.

Mehta, G., Hsiao, A. Y., Ingram, M., Luker, G. D., \& Takayama, S. (2012). Opportunities and challenges for use of tumor spheroids as models to test drug delivery and efficacy. Journal of Controlled Release, 164, 192-204.

Menendez, J. A., Vellon, L., Mehmi, I., Teng, P. K., Griggs, D. W., \& Lupu, R. (2005). A novel CYR61-triggered 'CYR61-alphavbeta3 integrin loop' regulates breast cancer cell survival and chemosensitivity through activation of ERK1/ERK2 MAPK signaling pathway. Oncogene, 24, 761-779.

Miller, J. S., Stevens, K. R., Yang, M. T., Baker, B. M., Nguyen, D. H., Cohen, D. M., ... Chen, C. S. (2012). Rapid casting of patterned vascular networks for perfusable engineered three-dimensional tissues. Nature Materials, 11, 768-774.

Moya, M., Tran, D., \& George, S. C. (2013). An integrated in vitro model of perfused tumor and cardiac tissue. Stem Cell Research \& Therapy, 4(Suppl. 1), S15.

Murray, M. J. (2015). Drosophila models of metastasis.

Naba, A., Clauser, K. R., Hoersch, S., Liu, H., Carr, S. A., \& Hynes, R. O. (2012). The matrisome: In silico definition and in vivo characterization by proteomics of normal and tumor extracellular matrices. Molecular \& Cellular Proteomics, 11(M111), 014647.

Naba, A., Clauser, K. R., Whittaker, C. A., Carr, S. A., Tanabe, K. K., \& Hynes, R. O. (2014). Extracellular matrix signatures of human primary metastatic colon cancers and their metastases to liver. BMC Cancer, 14, 518.

Nakazawa, K., Izumi, Y., \& Mori, R. (2009). Morphological and functional studies of rat hepatocytes on a hydrophobic or hydrophilic polydimethylsiloxane surface. Acta Biomaterialia, 5, 613-620.

Newbold, A., Martin, B. P., Cullinane, C., \& Bots, M. (2014). Detection of apoptotic cells using propidium iodide staining. Cold Spring Harbor Protocols, 2014, 1202-1206.

Nguyen, D. H., Stapleton, S. C., Yang, M. T., Cha, S. S., Choi, C. K., Galie, P. A., \& Chen, C. S. (2013). Biomimetic model to reconstitute angiogenic sprouting morphogenesis in vitro. Proceedings of the National Academy of Sciences of the United States of America, $110,6712-6717$.

Nugraha, B., Hong, X., Mo, X., Tan, L., Zhang, W., Chan, P. M., ... Yu, H. (2011). Galactosylated cellulosic sponge for multi-well drug safety testing. Biomaterials, 32, 6982-6994.

Nyga, A., Cheema, U., \& Loizidou, M. (2011). 3D tumour models: Novel in vitro approaches to cancer studies. Journal of Cell Communication and Signaling, 5, 239-248.

Oliveira, M. B., Neto, A. I., Correia, C. R., Rial-Hermida, M. I., Alvarez-Lorenzo, C., \& Mano, J. F. (2014). Superhydrophobic chips for cell spheroids high-throughput generation and drug screening. ACS Applied Materials \& Interfaces, 6, 9488-9495.

Orre, M., \& Rogers, P. A. (1999). Macrophages and microvessel density in tumors of the ovary. Gynecologic Oncology, 73, 47-50.

Ota, H., \& Miki, N. (2011). Microfluidic experimental platform for producing size-controlled three-dimensional spheroids. Sensors and Actuators A: Physical, 169, 266-273.

Pantel, K., \& Brakenhoff, R. H. (2004). Dissecting the metastatic cascade. Nature Reviews. Cancer, 4, 448-456.

Pathak, A., \& Kumar, S. (2012). Independent regulation of tumor cell migration by matrix stiffness and confinement. Proceedings of the National Academy of Sciences of the United States of America, 109, 10334-10339.

Premnath, P., Tan, B., \& Venkatakrishnan, K. (2015). Engineering functionalized multiphased silicon/silicon oxide nano-biomaterials to passivate the aggressive proliferation of cancer. Scientific Reports, 5, 12141.

Qiu, X., Zhang, Y., Zhao, X., Zhang, S., Wu, J., Guo, H., \& Hu, Y. (2015). Enhancement of endothelial differentiation of adipose derived mesenchymal stem cells by a threedimensional culture system of microwell. Biomaterials, 53, 600-608.

Sabeh, F., Shimizu-Hirota, R., \& Weiss, S. J. (2009). Protease-dependent versus -in dependent cancer cell invasion programs: Three-dimensional amoeboid movement revisited. The Journal of Cell Biology, 185, 11-19.
Santini, D., Tampellini, M., Vincenzi, B., Ibrahim, T., Ortega, C., Virzi, V., ... Tonini, G. (2012). Natural history of bone metastasis in colorectal cancer: Final results of a large Italian bone metastases study. Annals of Oncology, 23, 2072-2077.

Schuurman, W., Levett, P. A., Pot, M. W., van Weeren, P. R., Dhert, W. J., Hutmacher, D. W., ... Malda, J. (2013). Gelatin-methacrylamide hydrogels as potential biomaterials for fabrication of tissue-engineered cartilage constructs. Macromolecular Bioscience, $13,551-561$.

Sethi, T., Rintoul, R. C., Moore, S. M., MacKinnon, A. C., Salter, D., Choo, C., ... Haslett, C. (1999). Extracellular matrix proteins protect small cell lung cancer cells against apoptosis: A mechanism for small cell lung cancer growth and drug resistance in vivo. Nature Medicine, 5, 662-668.

Shield, K., Ackland, M. L., Ahmed, N., \& Rice, G. E. (2009). Multicellular spheroids in ovarian cancer metastases: Biology and pathology. Gynecologic Oncology, 113, $143-148$.

Silva-Correia, J., Miranda-Goncalves, V., Salgado, A. J., Sousa, N., Oliveira, J. M., Reis, R. M., \& Reis, R. L. (2012). Angiogenic potential of gellan-gum-based hydrogels for application in nucleus pulposus regeneration: In vivo study. Tissue Engineering. Part A, 18, 1203-1212.

Silva-Correia, J., Zavan, B., Vindigni, V., Silva, T. H., Oliveira, J. M., Abatangelo, G., \& Reis, R. L. (2013). Biocompatibility evaluation of ionic- and photo-crosslinked methacrylated gellan gum hydrogels: In vitro and in vivo study. Advanced Healthcare Materials, 2, 568-575.

Simi, A. K., Piotrowski, A. S., \& Nelson, C. M. (2015). Mechanotransduction, metastasis and genomic instability. Genomic instability and cancer metastasis (pp. 139-158). Springer.

Siolas, D., \& Hannon, G. J. (2013). Patient-derived tumor xenografts: Transforming clinical samples into mouse models. Cancer Research, 73, 5315-5319.

Song, H. H., Park, K. M., \& Gerecht, S. (2014). Hydrogels to model 3D in vitro microenvironment of tumor vascularization. Advanced Drug Delivery Reviews, 79-80, 19-29.

Stein, A. M., Demuth, T., Mobley, D., Berens, M., \& Sander, L. M. (2007). A mathematical model of glioblastoma tumor spheroid invasion in a three-dimensional in vitro experiment. Biophysical Journal, 92, 356-365.

Tentler, J. J., Tan, A. C., Weekes, C. D., Jimeno, A., Leong, S., Pitts, T. M., ... Eckhardt, S. G. (2012). Patient-derived tumour xenografts as models for oncology drug development. Nature Reviews. Clinical Oncology, 9, 338-350.

Thoma, C. R., Zimmermann, M., Agarkova, I., Kelm, J. M., \& Krek, W. (2014). 3D cell culture systems modeling tumor growth determinants in cancer target discovery. Advanced Drug Delivery Reviews, 69-70, 29-41.

Ursini-Siegel, J., \& Siegel, P. M. (2016). The influence of the pre-metastatic niche on breast cancer metastasis. Cancer Letters, 380, 281-288.

van de Wetering, M., Francies, H. E., Francis, J. M., Bounova, G., Iorio, F., Pronk, A., ... Clevers, H. (2015). Prospective derivation of a living organoid biobank of colorectal cancer patients. Cell, 161, 933-945.

van Marion, D. M., Domanska, U. M., Timmer-Bosscha, H., \& Walenkamp, A. M. (2016). Studying cancer metastasis: Existing models, challenges and future perspectives. Critical Reviews in Oncology/Hematology, 97, 107-117.

Vinci, M., Gowan, S., Boxall, F., Patterson, L., Zimmermann, M., Court, W., ... Eccles, S. A. (2012). Advances in establishment and analysis of three-dimensional tumor spheroidbased functional assays for target validation and drug evaluation. BMC Biology, $10,29$.

Vonlaufen, A., Joshi, S., Qu, C., Phillips, P. A., Xu, Z., Parker, N. R., ... Apte, M. V. (2008). Pancreatic stellate cells: Partners in crime with pancreatic cancer cells. Cancer Research, 68, 2085-2093.

Wang, X., Sun, L., Maffini, M. V., Soto, A., Sonnenschein, C., \& Kaplan, D. L. (2010). A complex 3D human tissue culture system based on mammary stromal cells and silk scaffolds for modeling breast morphogenesis and function. Biomaterials, 31, 3920-3929.

Ward, J. P., \& King, J. R. (2003). Mathematical modelling of drug transport in tumour multicell spheroids and monolayer cultures. Mathematical Biosciences, 181, 177-207.

White, R., Rose, K., \& Zon, L. (2013). Zebrafish cancer: The state of the art and the path forward. Nature Reviews. Cancer, 13, 624-636.

Williams, S. A., Anderson, W. C., Santaguida, M. T., \& Dylla, S. J. (2013). Patient-derived xenografts, the cancer stem cell paradigm, and cancer pathobiology in the 21st century. Laboratory Investigation, 93, 970-982.

Yan, L. P., Silva-Correia, J., Ribeiro, V. P., Miranda-Goncalves, V., Correia, C., da Silva Morais, A., ... Reis, R. L. (2016). Tumor growth suppression induced by biomimetic silk fibroin hydrogels. Scientific Reports, 6, 31037.

Yue, K., Trujillo-de Santiago, G., Alvarez, M. M., Tamayol, A., Annabi, N., \& Khademhosseini, A. (2015). Synthesis, properties, and biomedical applications of gelatin methacryloyl (GelMA) hydrogels. Biomaterials, 73, 254-271.

Zervantonakis, I. K., Hughes-Alford, S. K., Charest, J. L., Condeelis, J. S., Gertler, F. B., \& Kamm, R. D. (2012). Three-dimensional microfluidic model for tumor cell intravasation and endothelial barrier function. Proceedings of the National Academy of Sciences of the United States of America, 109, 13515-13520.

Zhang, M., Desai, T., \& Ferrari, M. (1998). Proteins and cells on PEG immobilized silicon surfaces. Biomaterials, 19, 953-960.

Zhang, Y. S., Duchamp, M., Oklu, R., Ellisen, L. W., Langer, R., \& Khademhosseini, A. (2016). Bioprinting the cancer microenvironment. ACS Biomaterials Science \& Engineering, 2, 1710-1721.

Zhu, W., Holmes, B., Glazer, R. I., \& Zhang, L. G. (2016). 3D printed nanocomposite matrix for the study of breast cancer bone metastasis. Nanomedicine, 12, 69-79. 